\title{
INFORMATION SHARING AND LEAKAGE IN THE TWO-ECHELON SUPPLY CHAIN
}

\author{
JingRU WANG, ZhiYUAN Zhen AND QIANG YAN*
}

\begin{abstract}
We consider ex post demand information sharing and leakage in a two-echelon supply chain consisting of one supplier and two retailers competing in quantities. The incumbent retailer has an advantage to acquire information about the market at a cost. If he invests in information acquisition, he privately acquires a signal about the market demand. We examine the incumbent's incentive of information acquisition and sharing, and the upstream supplier's information leakage strategy. We confirm that the incumbent's information acquisition and sharing decisions depend on whether the information acquisition is observable. When it is observable, the incumbent fully shares his private signals even though the shared high signal may hurt him. However, when it is unobservable, the incumbent can share the favorable signal (low signal) and withhold the unfavorable signal (high signal). Moreover, we also find that the supplier will always leak the signal to the entrant no matter what signal she acquires. In addition, we demonstrate under the information sharing and leakage strategy, it may benefit the whole supply chain when the retail competition intensity is not very large.
\end{abstract}

Mathematics Subject Classification. 35J20, 35J25, 35J60.

Received February 17, 2019. Accepted June 20, 2019.

\section{INTRODUCTION}

In order to better manage a supply chain, one should consider material flow, financial flow and information flow simultaneously in the supply chain. In previous studies, when the supply chain members make decisions, they have the same information (i.e., full information). However, in real practice, with various uncertain environments, full information is very rare and information asymmetry is everywhere (see [21,29]). To collect more information about the market, many companies and industries, such as Amazon and Wal-Mart have invested and installed data acquisition infrastructures (see [12]). Even though these data are converted into communicable information, it may be not perfect for the next sales season. As a result, some may not acquire or use their customer databases in making decisions like RadioShack Corp. and Toys R Us Inc. (see [9]). While other companies like Timberland, Hewlett-Packard, and IBM start to invest in data generating technologies to improve the precision of the data and make operation decisions more accurately (see [20]). In order to convert the data into information, many technological resources and efforts are needed. For example, the firm has to employ the market research personnel or data analysis experts to obtain and analyze the market data, which may lead a cost in generating valuable

\footnotetext{
Keywords. Supply chain management, information acquisition, demand information sharing, information leakage.

1 School of Business Administration, Hunan University, Changsha, Hunan 410082, PR China.

${ }^{*}$ Corresponding author: 15773135246@163.com
} 
information timely. Hence, if the cost of information acquisition is too high, the firm will give up information acquisition. The firm's investment and data collection cost cannot be observable to other supply chain firms.

Information will be exchanged and shared in the supply chain when some firms have private information (see $[3,6,36])$. Information sharing is an effective method to mitigate the bullwhip effect and improve efficiency of the supply chain (see $[1,27,37,39])$. However, the motivation for supply chain firms to publicly share their proprietary forecast information is not clear. On the one hand, many famous manufacturers like Proctor \& Gamble, Black Decker, take the initiative in collaboration with some retailers such as Wal-Mart and Home Depot. They develop the Collaborative Planning, Forecasting and Replenishment to share information in time (see [15]). On the other hand, many literatures show that many firms do not always be willing to share their private information. One reason for this phenomenon is that the receivers may abuse this information into their operation decisions to increase their own profits, which expands the double marginalization effect in the supply chain $[22,42]$. The other main reason is that the information may be leaked to the competitors directly or indirectly, which happens in many information platforms and industries.

Information leakage is very salient in the supply chain when the information is valuable (see [15]). In the 1990s, in order to get lower purchase price and save cost, GM leaked the product innovation to other suppliers without any permissions. In the survey of 447 automotive suppliers, Ward's 2007 shows that more than $28 \%$ of the suppliers affirm that the intellectual property of their firm is leaked by at least one Detroit automaker, and $16 \%$ of them say that it is leaked by transplant automakers (see [26]). Information leakage also widely exists in some industries (see [20,22,31]). For example, as described in Anand and Goyal [2], the upstream record companies (such as Sony, EMI, and Warner Music) tied up with artists to produce music, and sold part of the product to the market through the music retailers (such as Newbury Comics, Waterloo Records, Wal-Mart and HMV). Sound Scan, a typical third-party information collection company, generally tracked the music retailers' sales information to obtain the sales status of music CDS. The information was processed and transmitted to the upstream record companies subsequently. Newbury Comics, as the largest music retailer in the northeast US, always provided market demand and sales information to SoundScan every weekend from 1993 to 1999. However, in 1999 Newbury Comics discovered that SoundScan had leaked Newbury Comicss sales information to Handleman, another information collection company. Together with its own information, Handleman leaked sales information to its retailers including some Newbury Comics's rivals like Wal-mart, which hurts Newbury Comics. Therefore, Newbury Comics decided to stop sharing information with Sound Scan. Besides SoundScan, Newbury Comic's upstream supplier may also leak the information to its rivals. Figure 1 illustrates the sharing and leakage process of Newbury Comic's case.

Motivated by above phenomenon and practical cases, we focus on the impact of information sharing and leakage on each firms decisions and performance in a competing supply chain. We try to answer the following questions: When does the retailer invest in acquiring imperfect demand information at a cost? Does the retailer have an incentive to voluntarily share his acquired private information with the supplier when he takes the information leakage into account? How does the information leakage (direct or indirect) affect the information acquisition, sharing decisions and operation decisions (e.g., wholesale price and order quantities) in the supply chain? How does the entrant retailer infer demand information through the wholesale price? Does the supplier have an incentive to leak information directly? How do the competition intensity and information precision affect each firms information behavior and performance?

In order to answer the above questions, we consider a two-echelon supply chain consisting of one upstream supplier and two competing retailers. The incumbent retailer can choose to invest in information acquisition and observe the market demand at a cost. Other supply chain firms have no ways to acquire additional information unless the information is shared or leaked. If the incumbent retailer invests to acquire information, he can observe and acquire an imperfect signal about the market demand. Then the incumbent retailer can choose to disclose this signal to the supplier. The supplier may leak the demand signal to the entrant retailer if informed. Each firms information behavior and the retail competition between the two retailers can affect the operation decisions and performance in the supply chain. Our goal is to explore whether the incumbent retailer invests in information acquisition and shares his private information voluntarily with the upstream supplier. Moreover, 


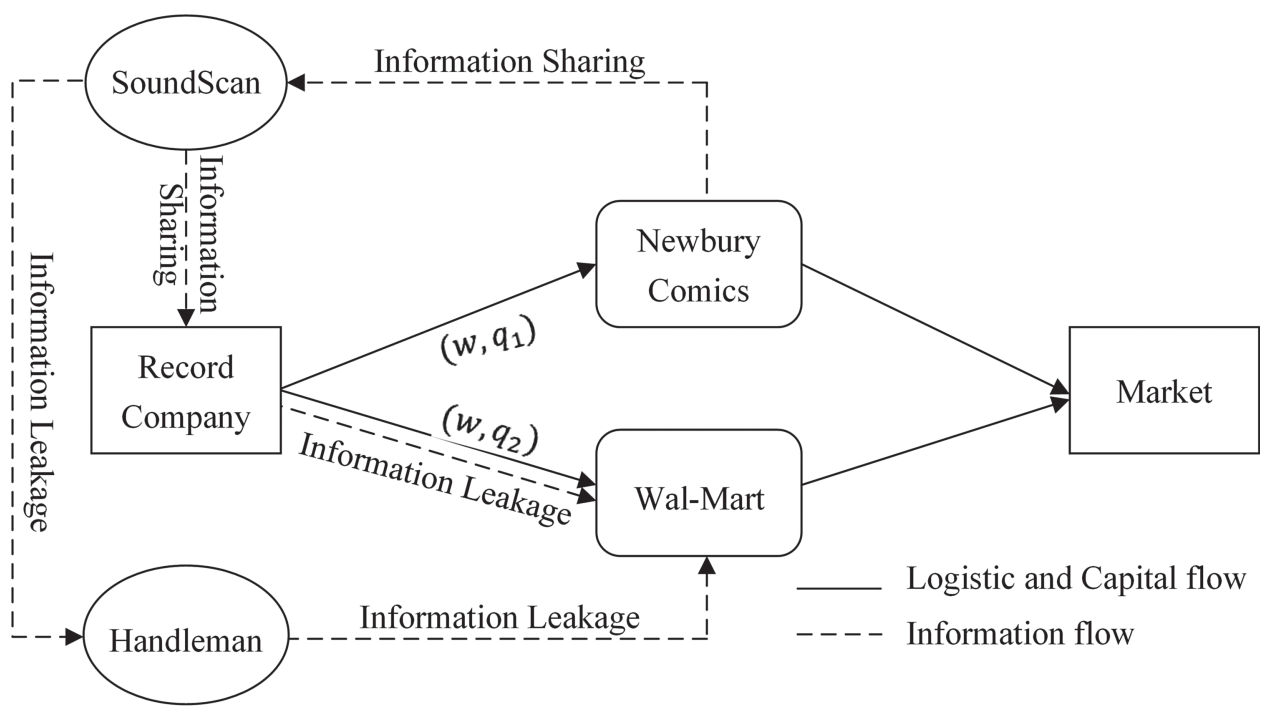

FiguRE 1. The process of information sharing and leakage.

we try to discuss the incentive of the supplier to leak the information to the entrant when she is informed, and find the factors that affect the information behavior and performance in the supply chain.

\section{Literature REVIEW}

Our work is closely related to the literature of information acquisition. Many researches demonstrate that information acquisition can improve each firm's ability to adjust the operation decisions in response to the uncertain market (see $[12,20]$ ). Most information sharing models involve exogenous information acquisition (see $[10,30,35])$. However, some researchers also study academic models involved endogenous information acquisition. Anand and Goyal [2] discuss the incentive for the incumbent retailer to acquire perfect demand information. They find that even the information acquisition is costless, the retailer may prefer not to acquire information due to the leakage of order information and competition. Guan and Chen [10] investigate the interplay between an upstream manufacture's information acquisition and quality disclosure. In their model, the firm can acquire perfect information without any cost. In contrast, the information acquisition in our model is imperfect and it may occur a cost. This information acquisition may affect each firm's the operation or strategy decisions in the supply chain. We try to find when the retailer chooses to invest in information acquisition.

This paper is also related to the literature of vertical information sharing. Information sharing can improve the supply chain efficiency. Many studies show that in a VMI setting, the retailer shares his demand and inventory information with the supplier, and the supplier decides how much to produce based on this information (see $[1,6,28])$. The VMI system utilizing information sharing benefits the supply chain performance while at least one firm may not get benefit from VIM (see [41]). Some studies discuss the incentive of information sharing. Li [22] and Zhang [42] discuss the retailer's incentive to share information with the supplier in a competing supply chain. They find that information sharing benefits the supplier but hurts the retailer. As a result, information sharing cannot be achieved. Similar results can also be found in Shamir [35], Bian et al. [4], Ha et al. [14], Shin and Tunca [34] and Shang et al. [33], Wu et al. [40] and Wang et al. [38]. Li and Zhang [23] examine the effect of confidentiality on the incentive of demand information sharing. These studies only consider the ex ante mandatory sharing in which the retailer commits to share all the information before he knows the content of the information. Chu et al. [10] study the ex post incentive of a retailer to share information with a make-to-stock supplier. They find that information sharing can be achieved under some conditions. In our paper, we focus 
TABLE 1. Related studies.

\begin{tabular}{|c|c|c|c|c|c|c|c|c|c|}
\hline Literature & $\begin{array}{l}\text { Downstream } \\
\text { competition }\end{array}$ & $\begin{array}{l}\text { Information } \\
\text { advantage }\end{array}$ & $\begin{array}{l}\text { Information } \\
\text { acquisition }\end{array}$ & $\begin{array}{l}\text { Acquisition } \\
\text { cost }\end{array}$ & $\begin{array}{l}\text { Signal } \\
\text { precision }\end{array}$ & $\begin{array}{l}\text { Sharing } \\
\text { arrangement }\end{array}$ & $\begin{array}{l}\text { Supplier } \\
\text { leakage }\end{array}$ & $\begin{array}{l}\text { Decision } \\
\text { variable }\end{array}$ & $\begin{array}{l}\text { Voluntary } \\
\text { sharing }\end{array}$ \\
\hline Zhang [42] & Imperfect & All retailers & Exogenous & No cost & Imperfect & Ex ante & Indirect & $(w, q)$ & Never \\
\hline $\mathrm{Li}[22]$ & Perfect & All retailers & Exog & No cost & Imperfect & Ex ante & Indire & $w, q)$ & Nev \\
\hline Li and Zhang [23] & Imperfect & All retailers & Exogenous & No cost & Imperfect & Ex ante & Indirect & $(w, p)$ & Always \\
\hline [35] & Perfect & All retailers & Exogenous & No cost & Imperfect & Ex ante & None & $(w, p)$ & Never \\
\hline Bian et al. [4] & Imperfect & All firms & Exogenous & No cost & Imperfect & Ex ante & None & $(w, q)$ & Never \\
\hline $\mathrm{Li}$ and Zhang [24] & None & Retailer & Exogenous & No cost & Imperfect & Ex ante & None & $(w, K, q)$ & Not always \\
\hline Shang et al. [33] & None & Retailer & Exogenous & No cost & Imperfect & Ex ante & None & $(w, q)$ & Not always \\
\hline Guo $[12]$ & None & Retailer & Exogenous & Yes & Perfect & Ex post & None & $(w, p)$ & Not always \\
\hline Guan and Chen [11] & None & Manufacturer & Endogenous & No cost & Perfect & Ex post & None & $(w, q)$ & Not always \\
\hline Shamir [30] & Perfect & All retailers & Exogenous & No cost & Imperfect & Ex post & Indirect & $(w, p)$ & Always \\
\hline Chu et al. [10] & None & Retailer & Exogenous & No cost & Perfect & Ex post & None & $(w, K, q)$ & Not always \\
\hline Anand and Goyal [2] & Perfect & Only one retailer & Endogenous & No cost & Perfect & Ex post & Direct & & Not always \\
\hline This paper & Imperfect & Only one retailer & Endogenous & Yes & Imperfect & Ex post & Direct, Indirect & $(w, q)$ & Not always \\
\hline
\end{tabular}

ex post voluntary information sharing in a competing supply chain and explore the effect of information sharing and leakage on the supplier's wholesale price and the retailers' order quantities. We show that under information sharing, each firm can adjust the operation decisions and the supplier becomes better to manage his production. Information asymmetry not only exists between the supplier and the retailer but also between two retailers.

In addition, some studies discuss the impact of leakage effect on the information sharing. Li [22] states that the retailers who choose not disclose their information with the supplier can infer other retailers' information from the wholesale price. This is called leakage effect. Kong et al. [18] find that revenue-sharing contract can prevent the supplier from information leakage. Other literature about information leakage can be found in Raza and Rathinam [28] and Zhang et al. [43]. Even though these papers consider the information leakage, they do not consider either the effect of information behavior on the suppliers operation or strategy decisions, which is our focus.

Table 1 summarizes the related studies and gives a comparative analysis. It shows that most of these studies focus on the ex ante information sharing. Under this ex ante information sharing arrangement, the retailer cannot make the decision strategically. Although some researchers study the ex post information sharing, the information acquisition is exogenous without any cost. Most studies either do not explore the information leakage or only consider the indirect information leakage through the wholesale price. Only Anand and Goyal [2] consider direct information leakage, but two retailers in their model order in sequence. The incumbents order quantity is disclosed to the supplier in a forced compliance way and the order information may be leaked by the supplier. Moreover, the suppliers wholesale price is exogenous and is not altered by the information behavior. In our model, the following issues are considered: (i) The retailers information acquisition is endogenous at a cost and is a decision variable. In addition, the acquired information is imperfect. (ii) Not all the retailers have information advantage. The only retailer who has private information can strategically decide whether to share it with the supplier after demand signal is acquired. (iii) In our model, we discuss both direct and indirect information leakage in a competing supply chain and explore the impact of the retail competition intensity on the decisions of information, which is not considered in their paper. (iv) The supplier's wholesale price and the retailers' order decisions are made after the information behavior. As a result, information strategies can affect each firm's operation decisions and performance in the supply chain.

The main contributions of our paper are summarized as follows: First, we examine the incentive of the incumbent retailer to acquire imperfect information at a cost. Most literature assumes that the firms' information acquisition is costless by default or the acquired information is perfect. In our model, the incumbent retailer's information acquisition is a decision variable and the acquired information is imperfect. Second, we discuss the incumbent retailer's information sharing strategy with voluntary compliance. We analyze the ex post information disclosure in which the incumbent makes his sharing decision after he acquires the demand signal. We find that in the ex post information disclosure, the incumbent's sharing strategy depends on whether the supplier can observe his information acquisition behavior and the content of the demand signal. Third, we analyze the 
information leakage between the supplier and the entrant retailer. The supplier adjusts her wholesale price according to the shared signal. Moreover, she can leak the signal to the entrant retailer directly. We find that although the supplier does not leak the signal directly, the entrant can infer the information indirectly from the wholesale price. In this way, it increases the double marginalization effect and hurts both the supplier and the retailers. These findings may have some important managerial implications for the supply chain firms in their information management and operation decisions.

The remainder of this paper is organized as follows. Section 3 describes the problem. Section 4 characterizes the model and evaluates the equilibrium decisions for each information scenario. Section 5 analyzes the incentive of incumbent retailer's information acquisition and sharing, and the incentive of the supplier's information leakage. Section 6 presents numerical examples to illustrate the theoretical findings. Finally, Section 7 concludes, and discusses the management insights derived from this paper. All formal proofs are included in the Appendix.

\section{PROBlem DESCRIPTION}

In this section, we describe the supply chain structure and market demand, notations and assumptions, information structure, and sequence of events in the supply chain.

\subsection{Supply chain structure and market demand}

We consider a two-echelon supply chain consisting of one supplier and two competing retailers: an incumbent retailer and an entrant retailer. The retailers source their common base product from the supplier at a wholesale price $w$, then they process it to substitutes. The supplier's marginal production cost is $c$. We respectively index the supplier, the incumbent retailer and the entrant retailer by $s, i$ and $e$. For convenience, we refer to the supplier as "she" and each retailer as 'he'. The retailers are engaged in a Cournot (quantity) competition. Following Li and Zhang [24], the inverse demand function for the market is given by

$$
p_{j}=A_{d}-q_{j}-\phi q_{k}, \text { for } j \neq k \text { and } j=i, e,
$$

where $\phi \in(0,1)$ denotes the substitutability of the products and indicates the competition intensity. $p_{i}$ and $p_{e}$ represent the retailers' retail prices, respectively. $q_{i}$ and $q_{e}$ represent their order quantities accordingly.

The intercept $A_{d}$ captures the state of the market demand. It takes one of two values: a high value $A_{H}$ with probability $\rho$ or a low value $A_{L}\left(A_{H}>A_{L}>c\right)$ with probability $(1-\rho)$. Assume that the distribution of $A_{d}$ is common knowledge. The expectation of $A_{d}$ is given by $\bar{A}=\rho A_{H}+(1-\rho) A_{L}$. This assumption of binary distribution is widely used in the information sharing game models (see $[2,5,10,11,13,24,30,32])$. The incentive and behavior of incomplete information sharing can be mainly represented under this simple distribution. Laffont and Martimort [19] demonstrate that the continuous distribution assumption does not alter the main results and provides very few additional insights. This also can be seen in Milgrom and Roberts [25] and they consider a limit-pricing game with a binary distribution and a continuous distribution, respectively. They show that the game becomes much more complexity under a continuous distribution. However, the main results are essentially the same. Moreover, the binary distribution is also widely applied in other fields. For example, Kannan [17] utilizes a binary distribution to discuss the effects of revelation policies in the procurement auction context.

Since the incumbent retailer stays longer in the market and is nearer to the consumers, he has more ways to acquire the demand information. Before the beginning of the selling season, the incumbent retailer can choose to observe the market demand $A_{d}$ and acquire a signal $Y$ at a cost $F$. Other firms cannot improve their belief about the market demand unless it is shared by the incumbent retailer. The structure of the supply chain is shown in Figure 2.

\subsection{Information Structure}

If the incumbent retailer invests in information acquisition, he can acquire a signal $Y$ about the demand state $A_{d}$. The signal takes two possible values, $h$ or $l$. It reflects the true demand state by the following conditional 


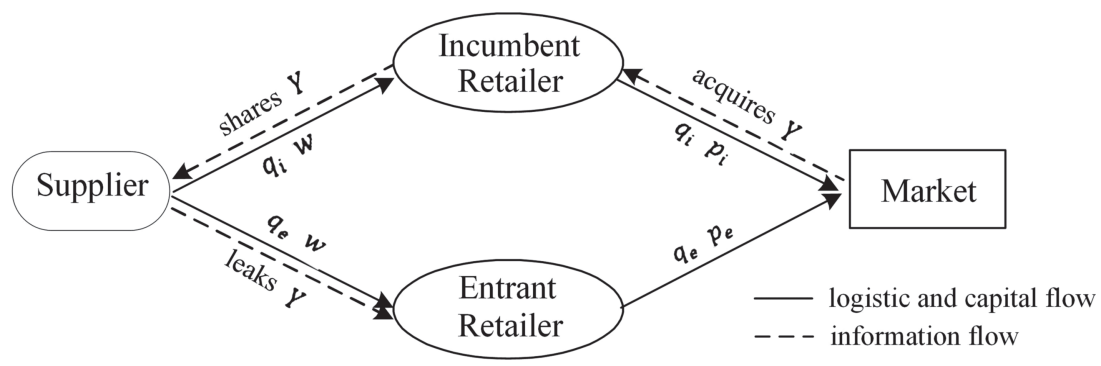

Figure 2. The supply chain structure.

probabilities, $\operatorname{Pr}\left(h \mid A_{H}\right)=\operatorname{Pr}\left(l \mid A_{L}\right)=\gamma$ with $0.5<\gamma \leq 1$. Similar information structure is commonly used in the literature to model the imperfect information (see $[24,32]$ ). According to Total Probability Theorem, the probabilities of the incumbent retailer to acquire the high signal and the low signal are $\lambda_{h}=\operatorname{Pr}(h)=$ $\rho \gamma+(1-\rho)(1-\gamma)$ and $\lambda_{l}=\operatorname{Pr}(l)=\rho(1-\gamma)+(1-\rho) \gamma$, respectively. It is easy to see $\lambda_{h}+\lambda_{l}=1$. Conditional on the signal $Y$, the Bayesian updated probabilities of the demand states are as following:

$$
\operatorname{Pr}\left(A_{H} \mid Y\right)= \begin{cases}\frac{\rho \gamma}{\rho \gamma+(1-\rho)(1-\gamma)}, & \text { if } Y=h, \\ \frac{\rho(1-\gamma)}{\rho(1-\gamma)+(1-\rho) \gamma}, & \text { if } Y=l .\end{cases}
$$

When $\gamma=\frac{1}{2}$, the posterior updated probability is the same as the prior. When $\gamma=1$, the signal is perfect. Note that the probabilities of $\operatorname{Pr}\left(A_{H} \mid h\right)$ and $\operatorname{Pr}\left(A_{L} \mid l\right)$ are increasing in $\gamma$. Hence, the parameter $\gamma$ indicates the signal precision. The signal $Y$ is always informative since $\gamma>0.5$. Conditional on the signal $Y$, the expectation of market demand state $A_{d}$ is $\hat{A_{H}}=E\left[A_{d} \mid h\right]=A_{H} \cdot \operatorname{Pr}\left(A_{H} \mid h\right)+A_{L} \cdot \operatorname{Pr}\left(A_{L} \mid h\right)$ and $\hat{A_{L}}=E\left[A_{d} \mid l\right]=A_{H} \cdot \operatorname{Pr}\left(A_{H} \mid l\right)+$ $A_{L} \cdot \operatorname{Pr}\left(A_{L} \mid l\right)$. Clearly, $\hat{A_{H}}>\bar{A}>\hat{A_{L}}>c$ and the expectation of $E\left[A_{d} \mid Y\right]$ is $E_{Y}\left[E\left[A_{d} \mid Y\right]\right]=\lambda_{h} E\left[A_{d} \mid h\right]+$ $\lambda_{l} E\left[A_{d} \mid l\right]=\bar{A}$. In Table 2, we summarize the notations throughout the paper. The subscript $N$ denotes that the incumbent retailer does not get any information signal. The subscript $h(l)$ denotes that the incumbent retailer gets a high (low) demand signal. We use superscript $k=1,2,3,4$ to index no information acquisition, information acquisition and no sharing, information sharing and indirect leakage, information sharing and direct leakage.

All firms are risk-neutral and aim to maximize their individual expected profits. For convenience, we assume that the retailers' marginal cost is constant and identical. Without loss of generality, we normalize it to zero. We consider that the supplier and the retailers take a long-term cooperation and care about their reputation, the disclosed information is truthful (see $[8,13])$. Hence, the information disclosure decision is either revealing the truth or remaining silent. Table 2 lists the notations in this paper.

\subsection{Sequence of events}

The sequence of events and decisions are as follows:

1. The incumbent retailer decides whether to invest in information acquisition. The cost of information acquisition is $F$. If $R_{i}$ invests, he acquires a signal $Y$ about $A_{d}$. Then the incumbent retailer decides whether to share the signal with the supplier.

2. If the supplier is informed, then she decides whether to leak it to the entrant retailer. Based on the signal and her information leakage behavior, the supplier sets a wholesale price $w$.

3. Upon observing $w$, both retailers determine their order quantities, i.e., $q_{i}$ for the incumbent retailer and $q_{e}$ for the entrant retailer. Then, the supplier produces and fulfills the downstream retailers' order quantities.

This three-stage game is similar to that found in Anand and Goyal [2] and Guo [12]. The information acquisition of the incumbent retailer captures two potential impacts. On the one hand, he can better adjust his 
TABLE 2. Notations and explanations.

\begin{tabular}{ll}
\hline \hline Notation & Explanations \\
\hline$A_{d}$ & Market demand state, $A_{d} \in\left\{A_{H}, A_{L}\right\}$. \\
$\bar{A}$ & Expectation of the market demand state. \\
$\rho$ & The probability of $A_{H}$. \\
$Y$ & The signal acquired by the incumbent retailer, $Y \in\{N, h, l\}$ \\
$\hat{A_{H}}\left(\hat{A_{L}}\right)$ & Expectation of the demand state condition on the signal $h(l)$. \\
$F$ & Incumbent retailer's information acquisition cost. \\
$c$ & Supplier's production cost. \\
$\phi$ & Competition intensity. \\
$q_{i}\left(q_{e}\right)$ & $R_{i}^{\prime} s\left(R_{e}^{\prime} s\right)$ order quantity. \\
$p_{i}\left(p_{e}\right)$ & $R_{i}^{\prime} s\left(R_{e}^{\prime} s\right)$ retail price. \\
$w_{Y}^{k}$ & Wholesale price condition on $Y$ in scenario $k, k=1,2,3,4$. \\
$q_{i Y}^{k}\left(q_{e Y}^{k}\right)$ & $R_{i}\left(R_{e}\right)^{\prime} s$ optimal order condition on $Y$ in scenario $k$. \\
$\pi_{i Y}^{k}\left(\pi_{e Y}^{k}\right)$ & $R_{i}\left(R_{e}\right)^{\prime} s$ expected profit condition on $Y$ in scenario $k$. \\
$\pi_{s Y}^{k}$ & Supplier's expected profit condition on $Y$ in scenario $k$. \\
$M_{R_{i}}$ & $R_{i}^{\prime} s$ overall information sharing set. \\
$M_{S}$ & Supplier's overall information disclosure set. \\
\hline
\end{tabular}

TABLE 3. Information available to the supply chain firms.

\begin{tabular}{llll}
\hline \hline Scenario & Incumbent retailer & Supplier & Entrant retailer \\
\hline S1 & $\mathrm{N}$ & $\mathrm{N}$ & $\mathrm{N}$ \\
S2 & $\mathrm{Y}$ & $\mathrm{N}$ & $\mathrm{N}$ \\
S3 & $\mathrm{Y}$ & $\mathrm{Y}$ & $w(Y)$ \\
S4 & $\mathrm{Y}$ & $\mathrm{Y}$ & $\mathrm{Y}$ \\
\hline
\end{tabular}

order quantity according to the signal. One the other hand, if $R_{i}$ shares the signal with the supplier, the supplier may leak it to the entrant retailer which may hurt the incumbent retailer. In our paper, information acquisition is a decision variable. In the stage 2 , whether the information acquisition is observable to the supplier directly affects the incumbent retailer's information sharing strategy. If it is observable to the supplier, the supplier can infer the hidden information which is hurtful for the incumbent retailer to share. If it is unobservable, the supplier cannot confirm whether the incumbent retailer conceals the information or he does not acquire information. Hence, we consider two situations: (i) the information acquisition is observable to the supplier; (ii) the information acquisition is unobservable.

Table 3 summarizes the information available to different firms in the supply chain in different disclosure scenarios. Note that "N" implies that the firm has no additional information besides the prior belief about the market demand. In Scenario 3, although the supplier does not leak the signal directly, the entrant retailer can infer some information from the wholesale price. Hence, there are two types of leakage behavior: leak information through the wholesale price $w$ (leakage effect) and leak the signal $Y$ directly (strategy effect).

\section{The MOdeL}

In this section, we try to solve the above three-stage game by using the backward induction approach for each scenario. We first analyze the retailers' order decisions given the wholesale price, and then derive the equilibria for the supplier's wholesale price. Based on these decisions, we evaluate the profit of each firm under 
different scenarios. Finally, we obtain the supplier's incentive of information leakage and the incumbent retailer's incentive of information sharing and acquisition, respectively.

\subsection{Scenario 1: No information acquisition}

The model is reduced to a standard two-stage game if the incumbent retailer does not acquire any information. The supply chain firms have the same information about the market demand as the prior. In the last stage, taking the wholesale price $w$, both retailers maximize their expected profits: $\pi_{i N}^{1}=\rho\left(A_{H}-q_{i}-\phi q_{e}-w\right) q_{i}+$ $(1-\rho)\left(A_{L}-q_{i}-\phi q_{e}-w\right) q_{i}$ and $\pi_{e N}^{1}=\rho\left(A_{H}-q_{e}-\phi q_{i}-w\right) q_{e}+(1-\rho)\left(A_{L}-q_{e}-\phi q_{i}-w\right) q_{e}$. The first term in the above equations indicates the retailers' profits under high demand state and the second term implies their profits under low demand state.

We can get the optimal order quantity of each retailer is $q_{i}(w)=q_{e}(w)=\frac{1}{2+\phi}(\bar{A}-w)$. The supplier's best response problem is $\max _{w} \pi_{s N}^{1}=\max _{w} E\left[(w-c)\left(q_{i}(w)+q_{e}(w)\right)\right]$, where $q_{i}(w)+q_{e}(w)$ means the total order quantity in the supply chain, $w-c$ implies the marginal profit of the supplier. We show that $\pi_{s N}^{1}$ is concave in $w$, according to the first order condition, the supplier's optimal wholesale price is $w_{N}^{1}=\frac{1}{2}(\bar{A}+c)$. The retailers' order quantities are $q_{i N}^{1}=q_{e N}^{1}=\frac{1}{2(2+\phi)}(\bar{A}-c)$. Based on the wholesale price and the retailer's order quantities, the profits of the supply chain firms in equilibrium are as follows:

$$
\pi_{i N}^{1}=\pi_{e N}^{1}=\frac{1}{4(2+\phi)^{2}}(\bar{A}-c)^{2} \text { and } \pi_{s N}^{1}=\frac{1}{2(2+\phi)}(\bar{A}-c)^{2} .
$$

\subsection{Scenario 2: Information acquisition and no sharing}

Under this scenario, the incumbent retailer chooses to invest in information acquisition. He acquires a signal $Y$ about the demand state $A_{d}$. However, the incumbent retailer does not share this signal with the supplier. In this way, although the supplier knows that the retailer acquires a signal, but she does not know the information content. Since $E_{Y}\left[E\left[A_{d} \mid Y\right]\right]=\bar{A}$, it is the same as the expectation of demand state with prior belief. Hence, the supplier retains her prior belief about the market. The incumbent retailer's expected profit is $\pi_{i Y}^{2}=E\left[\left(A_{d}-\right.\right.$ $\left.\left.q_{i}-\phi q_{e}-w\right) q_{i} \mid Y\right]-F, Y \in\{h, l\}$, where the first term indicates his expected profit based on the acquired signal $Y$ and the second term indicates his information acquisition cost. The entrant retailer's and the supplier's expected profits are $\pi_{e N}^{2}=E\left[\left(A_{d}-q_{e}-\phi E_{Y}\left(q_{i}\right)-w\right) q_{e}\right]$ and $\pi_{s N}^{2}=E\left[(w-c)\left(E_{Y}\left(q_{i}\right)+q_{e}\right)\right]$, respectively, where $E_{Y}\left(q_{i}\right)$ is the belief of the entrant retailer and the supplier on the incumbent retailer's order quantity. The equilibrium wholesale price is $w_{N}^{2}=\frac{1}{2}(\bar{A}+c)$ and the entrant retailer's order quantity is $q_{e N}^{2}=\frac{1}{2(2+\phi)}(\bar{A}-c)$, which are the same as in Scenario 1. The incumbent retailer's order quantity is $q_{i h}^{2}=\frac{1}{2} \hat{A_{H}}-\frac{(1+\phi)}{2(2+\phi)} \bar{A}-\frac{1}{2(2+\phi)} c$ for a high demand signal and $q_{i l}^{2}=\frac{1}{2} \hat{A_{L}}-\frac{(1+\phi)}{2(2+\phi)} \bar{A}-\frac{1}{2(2+\phi)} c$ for a low demand signal.

In order to make sure that $q_{i l}^{2}>0$, we assume $\hat{A_{L}}>\frac{1}{2+\phi}((1+\phi) \bar{A}+c)$, i.e. $(1+\phi) \lambda_{h}\left(\hat{A_{H}}-\right.$ $\left.\hat{A_{L}}\right)<\hat{A_{L}}-c$. This condition is equal to $\theta=\frac{A_{H}-c}{A_{L}-c}<\delta(\rho, \gamma, \phi, c)$, where $\delta(\rho, \gamma, \phi, c)=$ $\left\{\begin{array}{ll}\infty, & \text { if } \gamma<\frac{2+\phi-(1+\phi) \rho}{3+2 \phi-2 \rho(1+\phi)}, \\ \frac{(1-\rho)[(1+\phi) \rho-\gamma(1+2 \rho(1+\phi))]}{\rho[2+\phi-(1+\phi) \rho-\gamma(3+2 \phi-2 \rho(1+\phi))]}, & \text { if } \gamma>\frac{2+\phi-(1+\phi) \rho}{3+2 \phi-2 \rho(1+\phi)} .\end{array}\right.$ The parameter $\theta$ measures the market volatility. A greater $\theta$ means a larger volatility of the market demand. In equilibrium, the expected profits of the entrant retailer and the supplier are

$$
\pi_{e N}^{2}=\pi_{e N}^{1}=\frac{1}{4(2+\phi)^{2}}(\bar{A}-c)^{2} \text { and } \pi_{s N}^{2}=\pi_{s N}^{1}=\frac{1}{2(2+\phi)}(\bar{A}-c)^{2} .
$$

The incumbent retailer's profit is $\pi_{i Y}^{2}=\left(\frac{1}{2} E\left[A_{d} \mid Y\right]-\frac{1+\phi}{2(2+\phi)} \bar{A}-\frac{1}{2(2+\phi)} c\right)^{2}-F$ condition on the signal $Y$. 


\subsection{Scenario 3: Information sharing and indirectly leakage}

In this section, we suppose that the incumbent retailer shares his private signal $Y$ with the supplier and the supplier commits not to leak it. However, the supplier sets the wholesale price $w$ based on the signal $Y$. Although $R_{e}$ does not know $Y$, he will try to infer it from $w$. Note that $w(Y)$ is a strictly increasing function of $E\left[A_{d} \mid Y\right]$. We assume in equilibrium $w=f\left(E\left[A_{d} \mid Y\right]\right)$ for some strictly increasing and differentiable function $f(\cdot)$. We find the function through the steps described below. In equilibrium, the entrant $R_{e}$ takes $E\left[A_{d} \mid Y\right]$ to be equal to $f^{-1}(w)$. He substitutes $f^{-1}(w)$ for $E\left[A_{d} \mid Y\right]$ in his first order condition on his conjecture.

We have the following results: (i) When the signal $Y$ is $h$, the supplier will set the wholesale price $w_{h}^{3}=c+$ $\frac{6-\phi}{8}\left(\hat{A_{H}}-c\right)$. Both retailers order $q_{i h}^{3}=q_{e N}^{3}=\frac{1}{8}\left(\hat{A_{H}}-c\right)$. Based on the wholesale price and order quantities, the expected profits of supply chain parties are $\pi_{i h}^{3}=\frac{1}{64}\left(\hat{A_{H}}-c\right)^{2}-F, \pi_{e N}^{3}=\frac{1}{64}\left(\hat{A_{H}}-c\right)^{2}$ and $\pi_{s h}^{3}=\frac{6-\phi}{32}\left(\hat{A_{H}}-c\right)^{2}$; (ii) When the signal $Y$ is $l$, the supplier will set the wholesale price $w_{h}^{3}=c+\frac{6-\phi}{8}\left(\hat{A_{L}}-c\right)$. Both retailers order $q_{i l}^{3}=q_{e N}^{3}=\frac{1}{8}\left(\hat{A_{L}}-c\right)$. The profits of supply chain parties are $\pi_{i l}^{3}=\frac{1}{64}\left(\hat{A_{L}}-c\right)^{2}-F, \pi_{e N}^{3}=\frac{1}{64}\left(\hat{A_{L}}-c\right)^{2}$ and $\pi_{s l}^{3}=\frac{6-\phi}{32}\left(\hat{A_{L}}-c\right)^{2}$.

\subsection{Scenario 4: Information sharing and directly leakage}

In this section, we consider the situation that the supplier always leaks the signal $Y$ to the entrant retailer. In this case, $R_{i}$ takes $R_{e}^{\prime} s$ updated belief of the market demand into account. The entrant will adjust his order quantity after acquiring the signal. After learning the signal, the expected profits of the incumbent and entrant retailers are $\pi_{i Y}^{4}=E\left[\left(A_{d}-q_{i}-\phi q_{e}-w\right) q_{i} \mid Y\right]-F, Y \in\{h, l\}$ and $\pi_{e Y}^{4}=E\left[\left(A_{d}-q_{i}-\phi q_{e}-w\right) q_{i} \mid Y\right]$. The expected profit of the supplier is $\pi_{s Y}^{4}=E\left[(w-c)\left(q_{i}+q_{e}\right) \mid Y\right]$. All these profits are the expected profits conditional on the signal $Y$.

Suppose that the supplier always leaks the information signal directly to the entrant retailer, then we have the following equilibrium results: (i) The supplier's wholesale price is $w_{h}^{4}=\frac{1}{2}\left(\hat{A_{H}}+c\right)$ and both of the incumbent and entrant order $q_{i h}^{4}=q_{e h}^{4}=\frac{1}{2+\phi}\left(\hat{A_{H}}-c\right)$ when the signal is $h$; (ii) The supplier sets her wholesale price $w_{l}^{4}=\frac{1}{2}\left(\hat{A_{L}}+c\right)$ and both retailers order $q_{i l}^{4}=q_{e l}^{4}=\frac{1}{2+\phi}\left(\hat{A_{L}}-c\right)$ when the signal is $l$.

Based on the wholesale price and order quantities, then we have: (i) When the signal is $h$, the corresponding profits of supply chain parties are $\pi_{i h}^{4}=\frac{1}{4(2+\phi)^{2}}\left(\hat{A_{H}}-c\right)^{2}-F, \pi_{e h}^{4}=\frac{1}{4(2+\phi)^{2}}\left(\hat{A_{H}}-c\right)^{2}$, and $\pi_{s h}^{4}=\frac{1}{2(2+\phi)}\left(\hat{A_{H}}-c\right)^{2}$; (ii) When the signal is $l$, the profits are $\pi_{i l}^{4}=\frac{1}{4(2+\phi)^{2}}\left(\hat{A_{L}}-c\right)^{2}-F$, and $\pi_{s l}^{4}=\frac{1}{2(2+\phi)^{2}}\left(\hat{A_{L}}-c\right)^{2}$, respectively.

\section{The InCENTIVE of INFORMATION ACQUiSition, SHARING AND LEAKAgE}

Section 4 presents the equilibrium results under four different scenarios. In this section, we first analyze the information disclosure strategy of the supplier, then we consider whether the incumbent retailer voluntarily shares his private information signal. Finally, we get the condition under which the incumbent is willing to invest in information acquisition.

\subsection{The information disclosure strategy of the supplier}

As discussed above, the supplier may leak information in two ways. One is through the wholesale price and the other is telling $R_{i}^{\prime} s$ information signal directly. When the supplier acquires the signal from the incumbent retailer, she can choose to leak or not leak it to the entrant. Hence, for the supplier, her overall information disclosure set is $M_{S}=\{(h, l),(w(h), w(l))\}$. The next proposition gives the best information disclosure strategy.

Proposition 5.1. In equilibrium, the supplier will directly leak the signal to the entrant retailer no matter what signal she is shared from the incumbent, i.e. $(h, l)$.

Proposition 5.1 shows that the supplier is willing to convey the signal directly to the entrant retailer instead of leaking it through the wholesale price, no matter the signal is $h$ or $l$. When the supplier adjusts her wholesale price after acquiring the signal $Y$, she knows that the entrant retailer will infer the information from the 
wholesale price $w$. In this case, it increases the double marginalization effect among the supplier and both retailers, which is harmful to their profits.

Proposition 5.2. If the supplier is informed, in equilibrium, based on her information leakage strategy:

(i) The incumbent retailer is worse off with information sharing;

(ii) The entrant retailer is better off if the supplier is informed;

(iii) The supplier is better off with information sharing;

(iv) The supply chain's total profit is better off with information sharing if $0<\phi \leq \sqrt{3}-1$; but is worse off if $\sqrt{3}-1<\phi \leq 1$.

Proposition 5.2 shows that the incumbent retailer's equilibrium ex ante profit is lower with his information disclosure. The effect of information sharing is twofold: On the one hand, it can induce the supplier to choose a lower wholesale price when sharing a low information signal. On the other hand, when sharing a high information signal, the supplier will charge a higher wholesale price. The incumbent may realize that the supplier would leak it to his rival. A higher wholesale price will exaggerate the double marginalization, and the potential loss will exceed the benefit from the lower wholesale price.

The incumbent retailer's information acquirement can benefit both the upstream supplier and his rival if the supplier is informed. When the supplier acquires the signal from the incumbent retailer, she will choose to leak it to the entrant retailer and adjust her wholesale price accordingly to maximize her expected profit. When the supplier leaks the information to $R_{e}$, the entrant retailer may update his belief about the demand and adjust his order quantity according to the signal which benefits him for more accurate information.

For the supply chain's perspective, we can see that under the supplier's information leakage strategy, the supply chain's total profits may increase when the competition intensity $\phi$ is not very high. When the competition is too intense, the variation of the equilibrium wholesale prices would intensify the double marginalization problem and hurt the supply chain. Under other cases, the information sharing and disclosure can mitigate double marginalization effect and derive more profits.

\subsection{The information sharing strategy of the incumbent retailer}

According to Proposition 5.1, the supplier always leaks information if she is informed. In this section, we discuss that whether the incumbent retailer shares the signal with the supplier if acquiring information. The incumbent may share the favorable signal while withhold the unfavorable signal. The supplier will update her belief about the market potential when she is informed and then adjust the wholesale price strategically.

In this way, whether the supplier can observe the incumbent retailer's information acquisition behavior may directly affect the incumbent retailer's information disclosure setting. To be specific, if the supplier can observe whether the incumbent retailer acquires information signal, then the incumbent retailer's strategic information sharing setting $(h, l),(h, N)$ and $(N, l)$ are the same information disclosure strategy to the supplier. They are all the full information disclosure. However, if the supplier cannot observe, then in equilibrium $(h, l),(h, N)$ and $(N, l)$ are different setting to each other. For example, when the incumbent retailer voluntarily shares low demand signal, the feasible messages of high signal $((h, l)$ and $(N, l))$ are not equal. That is $h$ indicates a high demand state, and $N$ has two possible cases: one is that $R_{i}$ acquires the signal $h$ and withholds the signal, and the other is that $R_{i}$ does not acquire any signal. The following proposition shows the information sharing strategies of the incumbent retailer under two situations.

Proposition 5.3. Whether the supplier can observe the information acquisition behavior of the incumbent directly can affect $R_{i}^{\prime} s$ information sharing strategy:

(i) If information acquisition is observable to the supplier, then the possible information sharing strategy set of $R_{i}$ is $M_{R_{i}}=\{(h, l),(N, N)\}$. In equilibrium, the incumbent fully shares the signal, i.e., $(h, l)$; 
(ii) If information acquisition is unobservable to the supplier, then the overall information sharing strategy set of $R_{i}$ is $M_{R_{i}}=\{(h, l),(h, N),(N, l),(N, N)\}$. In equilibrium, the incumbent shares the low information signal and withholds the high signal, i.e., $(N, l)$.

Proposition 5.3 shows that no matter whether the supplier can observe the information acquisition behavior or not, the incumbent retailer always prefers to share the low information to induce a lower wholesale price. In turn, $R_{i}$ intends to keep silent when he observes a high information signal strategically. However, if the supplier can observe the information acquisition, she will infer that the information signal is $h$ when she is uninformed. In this way, the incumbent cannot withhold the high information signal. On the contrary, the incumbent retailer has the ability to withhold the high information signal if the supplier cannot observe the information acquisition. Because when the supplier is uninformed, she cannot infer whether $R_{i}$ conceals the unfavorable high information signal or does not acquire any information at all.

\subsection{The information acquisition of the incumbent retailer}

In this section, we discuss whether the incumbent chooses to invest in information acquisition. If the incumbent decides not to invest, then the information among supply chain parties are the same as prior and there is no information asymmetry. If the incumbent decides to invest, then he can observe the demand and acquire a signal $Y$. The incumbent retailer has an information advantage compared with the supplier and the entrant. He can share the favorable information with the supplier and withhold the unfavorable information. He can also realize that the supplier may leak the information to the entrant if he shares it to the supplier. Considering all these situations, the following proposition derives the equilibrium for the information acquisition.

Proposition 5.4. Whether the incumbent retailer decides to invest in information acquisition depends on the cost $F$ and the ability of the supplier observing the information acquisition behavior:

Case (i) If information acquisition is observable to the supplier and the cost of information acquisition satisfies $F \leq F_{1}=\frac{1}{4(2+\phi)^{2}}\left[\lambda_{h}\left(\hat{A}_{H}-c\right)^{2}+\lambda_{l}\left(\hat{A}_{L}-c\right)^{2}-(\bar{A}-c)^{2}\right]$, then $R_{i}$ will invest in information acquisition. There is no information asymmetry in equilibrium and all firms know the information signal.

Case (ii) If information acquisition is unobservable to the supplier and the cost of information acquisition satisfies $F \leq F_{2}=\frac{1}{4(2+\phi)^{2}}\left[\lambda_{h}\left(\hat{A}_{H}-c\right)^{2}+\lambda_{l}\left(\hat{A}_{L}-c\right)^{2}-(\bar{A}-c)^{2}+2 \lambda_{h}(1+\phi)\right.$ $\left.\left(\hat{A}_{H}-c\right)\left(\hat{A}_{H}-\bar{A}\right)+(1+\phi)^{2}\left(\hat{A}_{H}-\bar{A}\right)^{2}\right]$, then $R_{i}$ will invest in information acquisition. In this case, there is information asymmetry in equilibrium and the supplier and the entrant can only get a low signal.

Proposition 5.4 describes the condition that the incumbent retailer always invests in information acquisition, observes the market demand and gets an information signal $Y$. If the information acquisition cost $F$ satisfies $F \leq \min \left(F_{1}, F_{2}\right)$, even though the supplier can observe the information acquisition behavior and leak the signal $Y$ to the entrant retailer, the incumbent always acquires information to better know the market demand.

\section{NumERICAL EXAMPLES}

In this section, we illustrate these issues through a numerical example. Assume that $A_{H}=60, A_{L}=20$, $c=4, \rho=0.3$ and $\gamma=0.8$ (see [32]). The inverse demand function is $p_{j}=60-q_{j}-\phi q_{k}$ with probability 0.3 or $30-q_{j}-\phi q_{k}$ with probability 0.7 . Next, we will illustrate the main results in this paper.

Figure 3 shows that as the competition intensity $\phi$ increases, the supplier's profit decreases under each case. In addition, we find that no matter the received signal is $h$ or $l$, leaking the signal directly to the entrant makes the supplier better (i.e., $\pi_{s h}^{4}>\pi_{s h}^{3}, \pi_{s l}^{4}>\pi_{s l}^{3}$ ). As a result, the supplier prefers to leak the signal directly to the entrant if she is informed.

As shown in Figure 4, condition on the information leakage strategy, the ex-ante profit of the incumbent retailer is lower under information sharing while the ex-ante profits of the supplier and the entrant retailer 


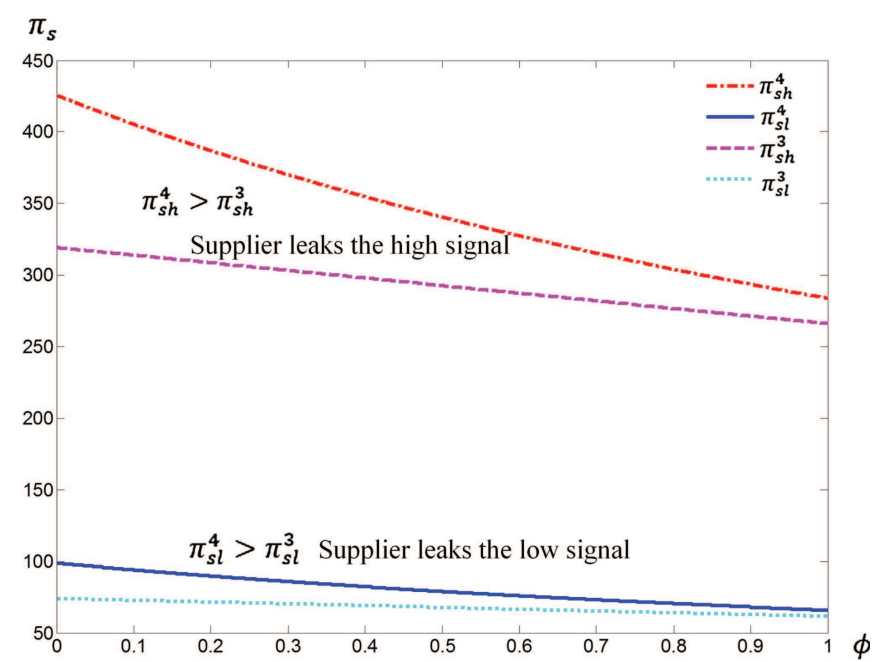

FiguRE 3. The supplier's information leakage strategy.

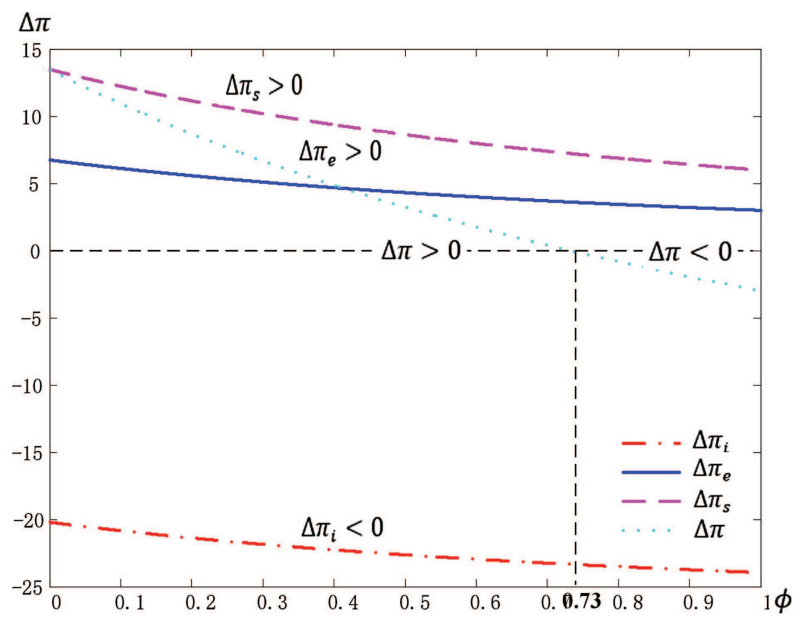

FiguRE 4. The effect of information sharing on the profits of supply chain firms and whole supply chain.

are higher. It means that both the supplier and the entrant benefit from the information sharing. However, under the ex-ante information sharing, the incumbent retailer has no incentive to share information voluntarily even though it is beneficial to the whole supply chain when the retail competition intensity is not very high $(0<\phi<\sqrt{3}-1 \approx 0.73)$.

Figure 4 shows that under ex ante information sharing, the incumbent has no incentive to share information. However, Figure 5 shows that the incumbent retailer is willing to share the low demand signal to get a low wholesale price under ex post information sharing and withhold the high information signal. However, if the supplier can observe the incumbent's information acquirement behavior, she can infer that the information signal must be high if she is uninformed.

As shown in Figures 6 and 7, the incumbent retailer does not always acquire information. If the cost of information acquisition is low, then the incumbent will invest in information acquisition even though he realizes 


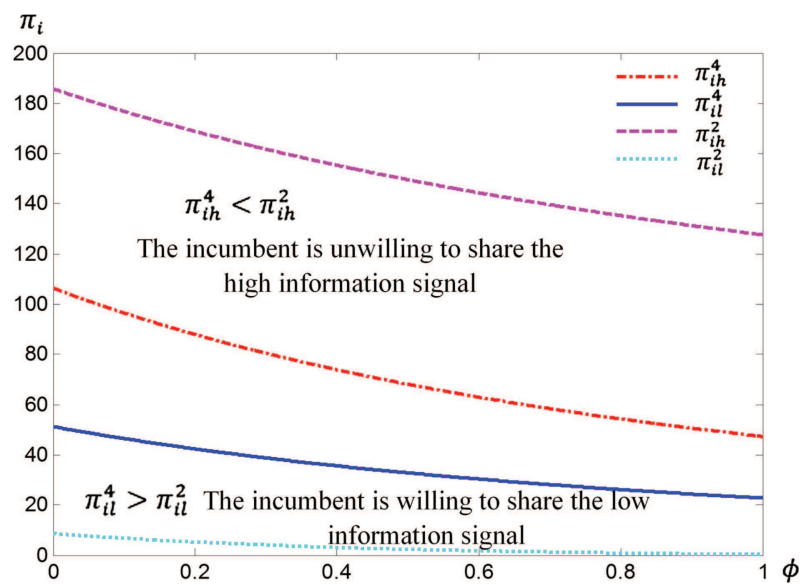

FiguRE 5. The incumbent retailer's information sharing strategy.

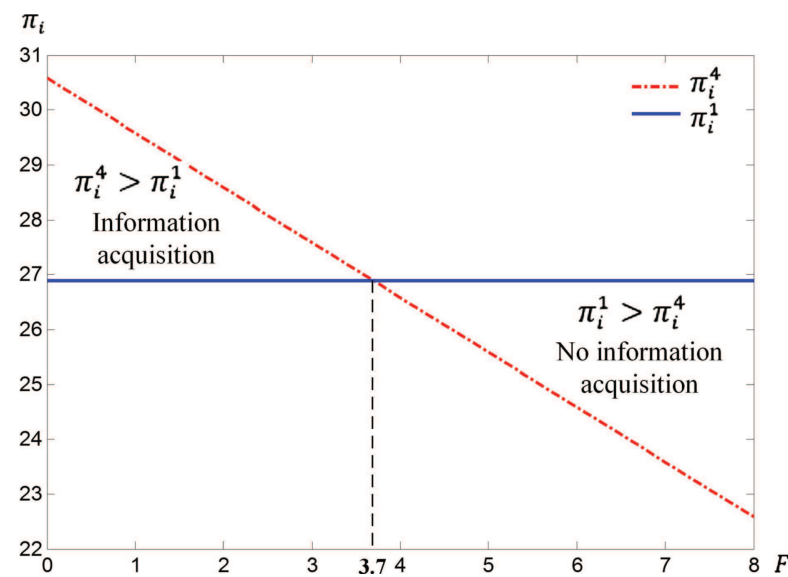

FiguRE 6 . The incumbent retailer's information acquisition decisions when information acquisition is observable $(\phi=0.7)$.

that the information is imperfect and may be leaked by the supplier to the competitor. However, if the cost of information acquisition is high, then the incumbent does not invest in information acquisition to mitigate the uncertainty of the market demand. Comparing the threshold of the information acquisition cost $F$ between Figures 6 and 7, we find that when the supplier cannot observe the incumbent's information acquisition behavior, then the incumbent is willing to pay more to invest in information acquisition (i.e., $F<34.6$ ) than that the supplier can observe (i.e., $F<3.7)$.

\section{Conclusions And management insights}

In this paper, we investigate the incumbent retailer's incentive to invest in information acquirement, information sharing strategy and the supplier's information leakage strategy in a two-echelon supply chain. Our paper is first to analyze information acquirement, sharing and leakage. The impact of information acquisition on the incumbent retailer is twofold. First, it can mitigate the market demand uncertainty and improve the order quantity even though the information signal is imperfect. Second, the incumbent retailer can share the 


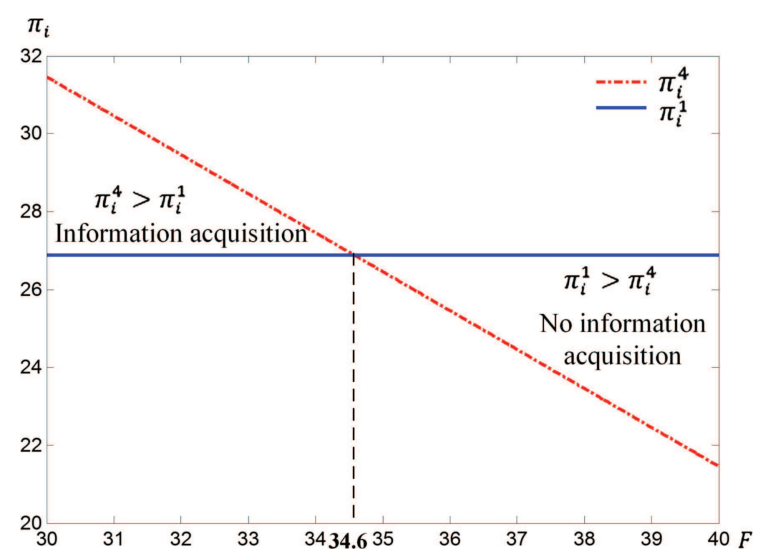

FIgURE 7. The incumbent retailer's information acquisition decisions when information acquisition is unobservable $(\phi=0.7)$.

signal with the upstream supplier to induce her to adjust wholesale price. However, information sharing leads the supplier to choose a lower wholesale price when the low information signal is shared, which is good for the incumbent retailer, but choose a higher wholesale price when the high signal is shared, which is bad for the incumbent retailer. Moreover, the supplier may leak the signal to his rival.

We find that the incumbent retailer's information acquirement and sharing strategy are related to whether the supplier can observe his information acquirement behavior. If the supplier cannot observe, it is easier to induce the incumbent retailer to invest in information acquirement because he can bear more information acquirement cost. Then he only shares the favorable information signal with the supplier (i.e., the low information signal). If she can observe, the incumbent retailer will share all information signal despite sharing high signal is bad for him. It is interesting to find that the supplier is more likely to leak the signal to the entrant retailer no matter what information signal is acquired. Because if she does not leak but adjust her wholesale price based on the information signal, then the entrant may infer the information from the wholesale price. In this way, it increases the double marginalization effect and even makes the supplier worse off.

Our work provides several management insights. First, with information sharing, the supplier will leak the signal directly if she is informed. Both the supplier and entrant retailer can benefit from information sharing while the incumbent retailer does not. Hence, the incumbent retailer is unlikely to ex ante share information even though it may improve the supply chain performance when the competition intensity is not very high. However, from an ex post perspective, the incumbent retailer voluntarily shares the low information signal. Second, the incumbent retailer's information acquisition and sharing strategy are dependent on whether the supplier can observe the information acquisition behavior. If the supplier cannot observe, it is easier to induce the incumbent to invest in information acquisition, he can share the favorable information signal but withhold the unfavorable signal. However, if she can observe, the retailer cannot withhold the unfavorable signal and share the signal he acquires.

The paper can be extended along the following possible directions. Different contracts like buyback contract, revenue-sharing contract and quantity-discount contract and so on, can be utilized to coordinate supply chain. It is interesting to investigate which contract can coordinate the supply chain. In addition, when there is multipleperiod interaction in the supply chain, how the information is updated and shared among the supply chain parties will be another interesting topic. 


\section{Appendix A. Proof of equilibrium Results in Scenario 3}

When the supplier is informed and adjusts her wholesale price appropriately, the entrant retailer can conjecture that the wholesale price is relevant to the information signal, i.e., $w=f\left(E\left(A_{d} \mid Y\right)\right)$, that is $E\left(A_{d} \mid Y\right)=f^{-1}(w)$. The function $f(\cdot)$ is a strictly increasing and differentiable function. In this way, the expected profits of the retailers are $\pi_{i Y}^{3}=\left(E\left(A_{d} \mid Y\right)-q_{i}-\phi E\left(q_{e} \mid Y\right)-w\right) q_{i}$ and $\pi_{e N}^{3}=\left(E\left(A_{d} \mid w\right)-q_{e}-\phi E\left(q_{i} \mid w\right)-w\right) q_{e}$.

The responses of the retailers satisfies the first-order conditions which is $q_{i}=\frac{1}{2}\left[E\left(A_{d} \mid Y\right)-\phi E\left(q_{e} \mid Y\right)-w\right]$ and $q_{e}=\frac{1}{2}\left[E\left(A_{d} \mid w\right)-\phi E\left(q_{i} \mid w\right)-w\right]$. The entrant $R_{e}$ would replace $E\left(A_{d} \mid w\right)$ with $f^{-1}(w)$, then the retailers' optimal order quantities are $q_{i}=\frac{1}{2} E\left(A_{d} \mid Y\right)-\frac{\phi}{2(2+\phi)} f^{-1}(w)-\frac{1}{2+\phi} w$ and $q_{e}=\frac{1}{2+\phi} f^{-1}(w)-\frac{1}{2+\phi} w$.

In this way, the expected profit of the supplier is $\pi_{s Y}^{3}=(w-c) E\left(q_{i}+q_{e} \mid Y\right)=(w-c)\left(\frac{1}{2} E\left(A_{d} \mid Y\right)+\right.$ $\left.\frac{2-\phi}{2(2+\phi)} f^{-1}(w)-\frac{2}{2+\phi} w\right)$. The supplier will choose a wholesale price to maximize her expected profit, which satisfies

$$
\frac{\mathrm{d} \pi_{s Y}^{3}}{\mathrm{~d} w}=\frac{1}{2} E\left(A_{d} \mid Y\right)+\frac{(2-\phi) f^{-1}(w)}{2(2+\phi)}-\frac{2 w}{2+\phi}+\frac{(2-\phi)(w-c)}{2(2+\phi)} \frac{\mathrm{d} f^{-1}(w)}{\mathrm{d} w}-\frac{2(w-c)}{2+\phi}=0 .
$$

Because $w=f\left(E\left(A_{d} \mid Y\right)\right)$ is an equilibrium, replace $E\left(A_{d} \mid Y\right)$ by $f^{-1}(w)$, then the condition of the first derivative also holds, that is

$$
\frac{1}{2} f^{-1}(w)+\frac{2-\phi}{2(2+\phi)} f^{-1}(w)-\frac{2 w}{2+\phi}+\frac{(2-\phi)(w-c)}{2(2+\phi)} \frac{\mathrm{d} f^{-1}(w)}{\mathrm{d} w}-\frac{2(w-c)}{2+\phi}=0 .
$$

It can simplify this equation to $\frac{\mathrm{d} f^{-1}(w)}{\mathrm{d} w}=-\frac{4}{(2-\phi)(w-c)} f^{-1}(w)+\frac{4(2 w-c)}{(2-\phi)(w-c)}$, and it is a first-order differential equation and the general solution is given by

$$
f^{-1}(w)=\frac{8}{6-\phi}(w-c)\left[1+Z(w-c)^{-\frac{6-\phi}{2-\phi}}\right]+c,
$$

where $Z$ is an arbitrary constant. Because $f(\cdot)$ is strictly increasing, we must have $Z \leq 0$. As mentioned above, an equilibrium wholesale price $w$ satisfies $f^{-1}(w)=E\left(A_{d} \mid Y\right)$, then we have

$$
(w-c)\left[1+Z(w-c)^{-\frac{6-\phi}{2-\phi}}\right]=\frac{6-\phi}{8}\left[E\left(A_{d} \mid Y\right)-c\right] .
$$

Next, we try to find a constant $Z$ to achieve the maximized expected profit. From the above equation we can show that $w(Z)=\frac{1}{2}\left(E\left(A_{d} \mid Y\right)+c\right)+\frac{2-\phi}{8}\left[E\left(A_{d} \mid Y\right)-c\right]-Z(w-c)^{-\frac{4}{2-\phi}}>\frac{1}{2}\left(E\left(A_{d} \mid Y\right)+c\right)$, since $Z \leq 0$. We replace $f^{-1}(w)$ to $E\left(A_{d} \mid Y\right)$ in the supplier's expected profit $\pi_{s Y}^{3}(w)=(w-c) \frac{2}{2+\phi}\left(E\left(A_{d} \mid Y\right)-w\right)$, we show that $\pi_{s Y}^{3}(w)$ is decreasing in $w$ when $w>\frac{1}{2}\left(E\left(A_{d} \mid Y\right)+c\right)$.

Define $G(w, Z)=w-c+Z(w-c)^{-\frac{4}{2-\phi}}-\frac{6-\phi}{8}\left[E\left(A_{d} \mid Y\right)-c\right]$, from the implicit function theorem, we can show that $w^{\prime}(Z)=-\frac{G_{Z}^{\prime}}{G_{w}^{\prime}}=-\frac{(w-c)^{-\frac{4}{2-\phi}}}{1-\frac{4 Z}{2-\phi}(w-c)^{-\frac{6-\phi}{2-\phi}}}<0$, which means $w(Z)$ is decreasing in $Z$. Hence, the supplier's expected profit is increasing in $Z \leq 0$, then the highest expected profit is obtained with $Z=0$ than any other equilibrium and the equilibrium wholesale price is $w_{Y}^{3}=c+\frac{6-\phi}{8}\left(E\left(A_{d} \mid Y\right)-c\right)$. Then we can get the expected profits of the supply chain parties which are in Section 4.3.

Proof of Proposition 1. The supplier can choose to leak the information signal to the entrant directly or make a commitment not to leak the signal after she is informed. Even though the supplier does not leak the signal directly, the entrant may infer the information signal $Y$ form $w$ depending on his belief that the information is a function of $w(Y)$.

In this way, if the supplier does not leak the signal, her expected profit is $\pi_{s h}^{3}=\frac{6-\phi}{32}\left(\hat{A}_{H}-c\right)^{2}$ when the high information signal is shared with the supplier, and $\pi_{s l}^{3}=\frac{6-\phi}{32}\left(\hat{A}_{L}-c\right)^{2}$ when the low information signal is shared; 
If the supplier leaks the signal to the entrant directly, then her expected profit is $\pi_{s h}^{4}=\frac{1}{2(2+\phi)}\left(\hat{A}_{H}-c\right)^{2}$ when the supplier acquires a high information signal, and $\pi_{s l}^{4}=\frac{1}{2(2+\phi)}\left(\hat{A}_{L}-c\right)^{2}$ when she acquires a low information signal.

Next, we analyze the supplier's information leakage strategy based on the incentive of the supplier to maximize her expected profit. We have

$$
\pi_{s h}^{4}-\pi_{s h}^{3}=\frac{1}{2(2+\phi)}\left(\hat{A}_{H}-c\right)^{2}-\frac{6-\phi}{32}\left(\hat{A}_{H}-c\right)^{2}=\frac{(2-\phi)^{2}}{32(2+\phi)}\left(\hat{A}_{H}-c\right)^{2}>0,
$$

and

$$
\pi_{s l}^{4}-\pi_{s l}^{3}=\frac{1}{2(2+\phi)}\left(\hat{A}_{L}-c\right)^{2}-\frac{6-\phi}{32}\left(\hat{A}_{L}-c\right)^{2}=\frac{(2-\phi)^{2}}{32(2+\phi)}\left(\hat{A}_{L}-c\right)^{2}>0 .
$$

Therefore, the supplier will always leak the information signal to the entrant directly no matter what information signal she acquires.

Proof of Proposition 2. When the incumbent retailer does not share any information signal with the supplier, then equilibrium expected ex ante profits are given by $\pi_{i}^{2}=\lambda_{h}\left(\frac{1}{2} \hat{A}_{H}-\frac{1+\phi}{2(2+\phi)} \bar{A}-\frac{1}{2(2+\phi)} c\right)^{2}+$ $\lambda_{l}\left(\frac{1}{2} \hat{A}_{L}-\frac{1+\phi}{2(2+\phi)} \bar{A}-\frac{1}{2(2+\phi)} c\right)^{2}-F, \pi_{e N}^{2}=\frac{1}{4(2+\phi)^{2}}(\bar{A}-c)^{2}$, and $\pi_{s N}^{2}=\frac{1}{2(2+\phi)}(\bar{A}-c)^{2}$. Then we have

$$
\begin{aligned}
\Delta \pi_{i}^{L 1}= & \pi_{i}^{4}-\pi_{i}^{2}=\frac{1}{4(2+\phi)^{2}}\left[\lambda_{h}\left(\hat{A}_{H}-c\right)^{2}+\lambda_{l}\left(\hat{A}_{L}-c\right)^{2}\right] \\
& -\lambda_{h}\left(\frac{1}{2} \hat{A}_{H}-\frac{1+\phi}{2(2+\phi)} \bar{A}-\frac{1}{2(2+\phi)} c\right)^{2}-\lambda_{l}\left(\frac{1}{2} \hat{A}_{L}-\frac{1+\phi}{2(2+\phi)} \bar{A}-\frac{1}{2(2+\phi)} c\right)^{2} \\
= & -\frac{1+\phi}{4(2+\phi)^{2}}\left\{\lambda_{h}\left[(1+\phi)\left(\hat{A}_{H}-\bar{A}\right)^{2}+2\left(\hat{A}_{H}-c\right)\left(\hat{A}_{H}-\bar{A}\right)\right]\right. \\
& \left.+\lambda_{l}\left[(1+\phi)\left(\hat{A}_{L}-\bar{A}\right)^{2}+2\left(\hat{A}_{L}-c\right)\left(\hat{A}_{L}-\bar{A}\right)\right]\right\} \\
= & -\frac{1+\phi}{4(2+\phi)^{2}}\left\{(1+\phi)\left[\lambda_{h}\left(\hat{A}_{H}-c\right)^{2}+\lambda_{l}\left(\hat{A}_{L}-c\right)^{2}\right]+2 \lambda_{h}\left(\hat{A}_{H}-\bar{A}\right)\left(\hat{A}_{H}-c\right)\right. \\
& \left.+2 \lambda_{l}\left(\hat{A}_{L}-\bar{A}\right)\left(\hat{A}_{L}-c\right)\right\} \\
= & -\frac{1+\phi}{4(2+\phi)^{2}}(3+\phi)\left[\lambda_{h}\left(\hat{A}_{H}-c\right)^{2}+\lambda_{l}\left(\hat{A}_{L}-c\right)^{2}-(\bar{A}-c)^{2}\right] .
\end{aligned}
$$

From the Jensen's Inequality, $\lambda_{h}\left(\hat{A}_{H}-c\right)^{2}+\lambda_{l}\left(\hat{A}_{L}-c\right)^{2}>\left[\lambda_{h}\left(\hat{A}_{H}-c\right)+\lambda_{l}\left(\hat{A}_{L}-c\right)\right]^{2}=(\bar{A}-c)^{2}$, then $\Delta \pi_{i}^{L 1}<0$.

(ii)

$$
\begin{aligned}
\Delta \pi_{e}^{L 1}=\pi_{e}^{4}-\pi_{e N}^{2} & =\frac{1}{4(2+\phi)^{2}}\left[\lambda_{h}\left(\hat{A}_{H}-c\right)^{2}+\lambda_{l}\left(\hat{A}_{L}-c\right)^{2}\right]-\frac{1}{4(2+\phi)^{2}}(\bar{A}-c)^{2} \\
& =\frac{1}{4(2+\phi)^{2}}\left[\lambda_{h}\left(\hat{A}_{H}-c\right)^{2}+\lambda_{l}\left(\hat{A}_{L}-c\right)^{2}-(\bar{A}-c)^{2}\right]>0 .
\end{aligned}
$$

(iii)

$$
\begin{aligned}
\Delta \pi_{s}^{L 1}=\pi_{s}^{4}-\pi_{s N}^{2} & =\frac{1}{2(2+\phi)}\left[\lambda_{h}\left(\hat{A}_{H}-c\right)^{2}+\lambda_{l}\left(\hat{A}_{L}-c\right)^{2}\right]-\frac{1}{2(2+\phi)}(\bar{A}-c)^{2} \\
& =\frac{1}{2(2+\phi)}\left[\lambda_{h}\left(\hat{A}_{H}-c\right)^{2}+\lambda_{l}\left(\hat{A}_{L}-c\right)^{2}-(\bar{A}-c)^{2}\right]>0 .
\end{aligned}
$$


(iv)

$$
\begin{aligned}
\Delta \pi^{L 1}= & \Delta \pi_{i}^{L 1}+\Delta \pi_{e}^{L 1}+\Delta \pi_{s}^{L 1} \\
= & -\frac{1+\phi}{4(2+\phi)^{2}}(3+\phi)\left[\lambda_{h}\left(\hat{A}_{H}-c\right)^{2}+\lambda_{l}\left(\hat{A}_{L}-c\right)^{2}-(\bar{A}-c)^{2}\right] \\
& +\frac{1}{4(2+\phi)^{2}}\left[\lambda_{h}\left(\hat{A}_{H}-c\right)^{2}+\lambda_{l}\left(\hat{A}_{L}-c\right)^{2}-(\bar{A}-c)^{2}\right] \\
& +\frac{1}{2(2+\phi)}\left[\lambda_{h}\left(\hat{A}_{H}-c\right)^{2}+\lambda_{l}\left(\hat{A}_{L}-c\right)^{2}-(\bar{A}-c)^{2}\right] \\
= & \frac{2-\phi^{2}-2 \phi}{4(2+\phi)^{2}}\left[\lambda_{h}\left(\hat{A}_{H}-c\right)^{2}+\lambda_{l}\left(\hat{A}_{L}-c\right)^{2}-(\bar{A}-c)^{2}\right],
\end{aligned}
$$

Case 1: If $0<\phi \leq \sqrt{3}-1$, then $2-\phi^{2}-2 \phi \geq 0$. We have $\Delta \pi^{L 1} \geq 0$.

Case 2: If $\sqrt{3}-1<\phi \leq 1$, then $2-\phi^{2}-2 \phi<0$. We have $\Delta \pi^{L 1} \leq 0$.

Proof of Proposition 3. We consider the scenario that $R_{i}$ chooses to invest in information acquirement. Taking the supplier's wholesale price and the retailers' order quantities into account, we have

Case (i) when $R_{i}$ does not share the information signal with the supplier, then $R_{i}^{\prime} s$ expected profit is $\pi_{i h}^{2}$ if she observes a high information signal and $\pi_{i l}^{2}$ if she observes a low information signal. In this situation, $R_{e}^{\prime} s$ expected profit is $\pi_{e N}^{2}$ and the supplier's expected profit is $\pi_{s N}^{2}$.

Case (ii) when $R_{i}$ shares the information signal with the supplier, then he will realize that the supplier will leak the high information to the entrant. In this way, the expected profits of the supply chain players are $\pi_{i h}^{4}, \pi_{e h}^{4}$ and $\pi_{s h}^{4}$ if the high information signal is shared but $\pi_{i l}^{4}, \pi_{e l}^{4}$ and $\pi_{s l}^{4}$ if the low information signal is shared.

Next, we derive the ex post information sharing incentive of the incumbent. Comparing $R_{i}$ 's expected profits between these two cases, we have

$$
\begin{aligned}
\pi_{i h}^{4}-\pi_{i h}^{2} & =\frac{1}{4(2+\phi)^{2}}\left(\hat{A}_{H}-c\right)^{2}-\left(\frac{1}{2} \hat{A}_{H}-\frac{1+\phi}{2(2+\phi)} \bar{A}-\frac{1}{2(2+\phi)} c\right)^{2} \\
& =-\left[\frac{(1+\phi)^{2}\left(\hat{A}_{H}-\bar{A}\right)^{2}}{4(2+\phi)^{2}}+\frac{1+\phi}{2(2+\phi)^{2}}\left(\hat{A}_{H}-c\right)\left(\hat{A}_{H}-\bar{A}\right)\right]<0,
\end{aligned}
$$

i.e. $\pi_{i h}^{4}<\pi_{i h}^{2}$.

$$
\begin{aligned}
\pi_{i l}^{4}-\pi_{i l}^{2} & =\frac{1}{4(2+\phi)^{2}}\left(\hat{A}_{L}-c\right)^{2}-\left(\frac{1}{2} \hat{A}_{L}-\frac{1+\phi}{2(2+\phi)} \bar{A}-\frac{1}{2(2+\phi)} c\right)^{2} \\
& =-\frac{(1+\phi)}{4(2+\phi)^{2}}\left(\hat{A}_{L}-\bar{A}\right)\left[(1+\phi)\left(\hat{A}_{L}-\bar{A}\right)+2\left(\hat{A}_{L}-c\right)\right] \\
& =\frac{(1+\phi)}{4(2+\phi)^{2}}\left(\bar{A}-\hat{A}_{L}\right)(\bar{A}-c)\left[(3+\phi) \frac{\hat{A}_{L}-c}{\bar{A}-c}-(1+\phi)\right] .
\end{aligned}
$$

Since $\hat{A}_{L}>\frac{1}{2+\phi}((1+\phi) \bar{A}+c)$, then $\frac{\hat{A}_{L}-c}{A-c}>\frac{1+\phi}{2+\phi}$. We can show that

$$
\begin{aligned}
\pi_{i l}^{4}-\pi_{i l}^{2} & =\frac{(1+\phi)}{4(2+\phi)^{2}}\left(\bar{A}-\hat{A}_{L}\right)(\bar{A}-c)\left[(3+\phi) \frac{\hat{A}_{L}-c}{\bar{A}-c}-(1+\phi)\right] \\
& >\frac{(1+\phi)}{4(2+\phi)^{2}}\left(\bar{A}-\hat{A}_{L}\right)(\bar{A}-c)\left[(3+\phi) \frac{1+\phi}{2+\phi}-(1+\phi)\right] \\
& =\frac{(1+\phi)}{4(2+\phi)^{3}}\left(\bar{A}-\hat{A}_{L}\right)(\bar{A}-c)>0,
\end{aligned}
$$


i.e. $\pi_{i l}^{4}>\pi_{i l}^{2}$.

Hence the incumbent voluntarily shares the low information signal with the supplier even though he may realize that the supplier will leak it to the entrant. But the incumbent wants to withhold the high information signal to prevent the supplier from setting a higher wholesale price. However, if the supplier can observe $R_{i}$ 's information acquisition, then when she is uninformed, she can infer a high information signal is observed by the incumbent. Therefore, $R_{i}$ 's equilibrium information sharing strategy is dependent on whether the supplier can observe the information acquisition behavior. If the supplier can observe this behavior, then the equilibrium information sharing strategy of the incumbent is $(h, l)$; Otherwise, the equilibrium is $(N, l)$.

Proof of Proposition 4. Taking the information sharing and information leakage strategies into consideration, the incumbent retailer chooses to whether invest in information acquirement or not. Since $R_{i}$ 's information sharing strategy is dependent on whether the supplier can observe the information acquisition behavior, according to Propositions 5.1 and 5.3, we have

(i) When the supplier can observe $R_{i}$ 's information acquisition behavior, then in equilibrium, $R_{i}$ 's information sharing strategy and the supplier's information leakage strategy are both $(h, l)$. In this way, the expected profit of the incumbent is $\pi_{i}^{4}=\frac{1}{4(2+\phi)^{2}}\left[\lambda_{h}\left(\hat{A}_{H}-c\right)^{2}+\lambda_{l}\left(\hat{A}_{L}-c\right)^{2}\right]-F$. Hence, the incumbent has an incentive to invest in information acquisition and observe the market demand if and only if $\pi_{i}^{4} \geq \pi_{i N}^{1}$, which is equal to $F \leq F_{1}=\frac{1}{4(2+\phi)^{2}}\left[\lambda_{h}\left(\hat{A}_{H}-c\right)^{2}+\lambda_{l}\left(\hat{A}_{L}-c\right)^{2}-(\bar{A}-c)^{2}\right]$.

When the supplier cannot observe the behavior, then in equilibrium, $R_{i}$ 's information sharing strategy and the supplier's information leakage strategy are both $(N, l)$. Then the expected profit of the incumbent is $\pi_{i}^{4}=$ $\lambda_{h}\left(\frac{1}{2} \hat{A}_{H}-\frac{1+\phi}{2(2+\phi)} \bar{A}-\frac{1}{2(2+\phi)} c\right)^{2}+\lambda_{l} \frac{1}{4(2+\phi)^{2}}\left(\hat{A}_{L}-c\right)^{2}-F$. Hence, $R_{i}$ has an incentive to invest if and only if $\pi_{i}^{4} \geq \pi_{i}^{1}$ which is $F \leq F_{2}=\frac{1}{4(2+\phi)^{2}}\left[\lambda_{h}\left(\hat{A}_{H}-c\right)^{2}+\lambda_{l}\left(\hat{A}_{L}-c\right)^{2}-(\hat{A}-c)^{2}+2 \lambda_{h}(1+\phi)\left(\hat{A}_{H}-c\right)\left(\hat{A}_{H}-\bar{A}\right)+\right.$ $\left.(1+\phi)^{2}\left(\hat{A}_{H}-\bar{A}\right)^{2}\right]$.

Acknowledgements. The research is supported by the National Natural Science Foundation of China under Grant Nos. 71571065,71790593 and 71521061.

\section{REFERENCES}

[1] A.H. Afshar Sedigh, R. Haji and S.M. Sajadifar, Cost function and optimal boundaries for a two-level inventory system with information sharing and two identical retailers. Sci. Iran. 26 (2019) 472-485.

[2] K.S. Anand and M. Goyal, Strategic information management under leakage in a supply chain. Manage. Sci. 55 (2009) $438-452$.

[3] P. Baruah, R.B. Chinnam, A. Korostelev and E. Dalkiran, Optimal soft-order revisions under demand and supply uncertainty and upstream information. Int. J. Prod. Econ. 182 (2016) 14-25.

[4] W. Bian, J. Shang and J. Zhang, Two-way information sharing under supply chain competition. Int. J. Prod. Econ. 178 (2016) $82-94$.

[5] G.P. Cachon and M.A. Lariviere, Contracting to assure supply: how to share demand forecast in a supply chain. Manage. Sci. 47 (2001) 629-646.

[6] S. Cannella, J.M. Framinan, M. Bruccoleri, A.P. Barbosa-Pvoa and S. Relvas, The effect of inventory record inaccuracy in information exchange supply chains. Eur. J. Oper. Res. 243 (2015) 120-129.

[7] F. Chen, G. Lai and W. Xiao, Provision of incentives for information acquisition: forecast-based contracts vs. menus of linear contracts. Manage. Sci. 62 (2016) 1899-1914.

[8] W.H.J. Chu and C.C. Lee, Strategic information sharing in a supply chain. Eur. J. Oper. Res. 174 (2006) 1567-1579.

[9] S. Collett, Turning data into dollars. Computerworld 38 (2004) 36-37.

[10] L.Y. Chu, N. Shamir and H. Shin, Strategic communication for capacity alignment with pricing in a supply chain. Manage. Sci. 63 (2017) 4366-4388.

[11] X. Guan and Y.J. Chen, The interplay between information acquisition and quality disclosure. Prod. Oper. Manage. 26 (2017) $389-408$.

[12] L. Guo, The benefits of downstream information acquisition. Mark. Sci. 28 (2009) 457-471.

[13] L. Guo and G. Iyer, Information acquisition and sharing in a vertical relationship. Mark. Sci. 29 (2010) $483-506$.

[14] A.Y. Ha, S. Tong and H. Zhang, Sharing imperfect demand information in competing supply chains with production diseconomies. Manage. Sci. 57 (2011) 566-581. 
[15] C.L. Hay, What Wal-Mart Knows about Customers Habits. New York Times, November 14 (2004).

[16] S. Huang and J. Yang, Information acquisition and transparency in a supply chain with asymmetric production cost information. Int. J. Prod. Econ. 182 (2016) 449-464.

[17] K.N. Kannan, Effects of information revelation policies under cost uncertainty. Inf. Syst. Res. 23 (2012) 75-92.

[18] G. Kong, S. Rajagopalan and H. Zhang, Revenue sharing and information leakage in a supply chain. Manage. Sci. 59 (2013) $556-572$.

[19] J. Laffont and D. Martimort, The Theory of Incentives. The Principal Agent Model. Princeton University Press, Princeton, NJ (2002)

[20] H.L. Lee and S. Whang, Information sharing in a supply chain. Int. J. Technol. Manage. 20 (2000) 373-387.

[21] C.Y. Lee and R.Yang, Supply chain contracting with competing suppliers under asymmetric information. IIE Trans. 45 (2013) $25-52$.

[22] L. Li, Information sharing in a supply chain with horizontal competition. Manage. Sci. 48 (2002) $1196-1212$.

[23] L. Li and H. Zhang, Confidentiality and Information sharing in supply chain coordination. Manage. Sci. 54 (2008) $1467-1481$.

[24] T. Li and H. Zhang, Information sharing in a supply chain with a make-to-stock manufacturer. Omega 50 (2015) 115-125.

[25] P. Milgrom and J. Roberts, Limit pricing and entry under incomplete information: An equilibrium analysis. Econometrica 50 (1982) 443-459.

[26] T. Murphy, Protection in Question. Survey: Detroit Compromises Intellectual Property. Wards AutoWorld (2007) $20-21$.

[27] D. Ojh, F. Sahin, J. Shockley and S.V. Sridharan, Is there a performance tradeoff in managing order fulfillment and the bullwhip effect in supply chains? The role of information sharing and information type. Int. J. Prod. Econ. 208 (2019) 529-543.

[28] S.A. Raza and S. Rathinam, A risk tolerance analysis for a joint price differentiation and inventory decisions problem with demand leakage effect. Int. J. Prod. Econ. 183 (2017) 129-145.

[29] W. Schmidt, Supply chain disruptions and the role of information asymmetry. Dec. Sci. 46 (2015) 465-475.

[30] N. Shamir, Cartel formation through strategic information leakage in a distribution channel. Mark. Sci. 36 (2017) 70-88.

[31] T. Singer, Sharer Beware: Are You Giving Too Much Information About Your Business. Inc. March (1999).

[32] N. Shamir and H. Shin, Public forecast information sharing in a market with competing supply chains. Manage. Sci. 62 (2016) 2994-3022.

[33] W. Shang, A.Y. Ha and S. Tong, Information sharing in a supply chain with a common retailer. Manage. Sci. 62 (2016) 245-263.

[34] H. Shin and T.I. Tunca, Do firms invest in forecasting efficiently? The effect of competition on demand forecast investments and supply chain coordination. Oper. Res. 58 (2010) 1592-1610.

[35] N. Shamir, Strategic information sharing between competing retailers in a supply chain with endogenous wholesale price. Int. J. Prod. Econ. 136 (2012) 352-365.

[36] M. Shnaiderman and F. Ouardighi, The impact of partial information sharing in a two-echelon supply chain. Oper. Res. Lett. 42 (2014) 234-237.

[37] R.H. Teunter, M.Z. Babai, J.A.C. Bokhorst and A.A. Syntetos, Revisiting the value of information sharing in two-stage supply chains. Eur. J. Oper. Res. 270 (2018) 1044-1052.

[38] J.C. Wang, Y.Y. Wang and T. Che, Information sharing and the impact of shutdown policy in a supply chain with market disruption risk in the social media era. Inf. Manage. 56 (2019) 280-293.

[39] J. Wei, J. Zhao and X. Hou, Bilateral information sharing in two supply chains with complementary products. Appl. Math. Model. 72 (2019) 28-49.

[40] J. Wu, F. Jiang and Y. He, Pricing and horizontal information sharing in a supply chain with capacity constraint. Oper. Res. Lett. 46 (2018) 402-408.

[41] H. Yu, A.Z. Zeng and L. Zhao, Analyzing the evolutionary stability of the vendor -managed inventory supply chains. Comput. Ind. Eng. 56 (2009) 274-282.

[42] H. Zhang, Vertical information exchange in a supply chain with duopoly retailers. Prod. Oper. Manage. 11 (2002) 531-546.

[43] D.Y. Zhang, Y. Zeng, L. Wang, H. Li and Y. Geng, Modeling and evaluating information leakage caused by inferences in supply chains. Comput. Ind. 62 (2011) 351-363. 